\title{
Hydrogen Peroxide Improves the Visibility of Ulcer Bases in Acute Non-variceal Upper Gastrointestinal Bleeding: A Single-Center Prospective Study
}

\author{
Subbaramiah Sridhar · Sherman Chamberlain · Dharma Thiruvaiyaru • \\ Sankara Sethuraman · Jigneshkumar Patel · Moonkyung Schubert · \\ Francisco Cuartas-Hoyos · Robert Schade
}

Received: 7 June 2009/ Accepted: 6 August 2009/Published online: 10 September 2009

(c) The Author(s) 2009. This article is published with open access at Springerlink.com

\begin{abstract}
Background Acute non-variceal upper gastrointestinal bleeding (ANVB) or hemorrhage (used interchangeably) is an emergency. Endoscopically applied hydrogen peroxide $\left(\mathrm{H}_{2} \mathrm{O}_{2}\right)$ has been shown to improve visualization of the ulcer base.

Aims To test the hypothesis that ulcer base clot clearance with $3 \% \mathrm{H}_{2} \mathrm{O}_{2}$ improves the visualization of ANVB lesions compared to water alone.
\end{abstract}

The preliminary results of the study were presented at the Plenary Session of the Annual ACG Meeting (October 2005) and received the "Governor's Award for Excellence in Clinical Research."

S. Sridhar $(\bowtie) \cdot$ S. Chamberlain $\cdot$ J. Patel $\cdot$ M. Schubert .

F. Cuartas-Hoyos · R. Schade

Section of Gastroenterology and Hepatology, Medical College

of Georgia, Augusta, GA, USA

e-mail: ssridhar@mcg.edu; ssridhar96@gmail.com

S. Chamberlain

e-mail: schamberlain@mcg.edu

J. Patel

e-mail: jpatel@mcg.edu

M. Schubert

e-mail: msschubert@mcg.edu

F. Cuartas-Hoyos

e-mail: fcuartas@mcg.edu

R. Schade

e-mail: rschade@mcg.edu

D. Thiruvaiyaru $\cdot$ S. Sethuraman

Mathematics and Computer Science, Augusta State University,

Augusta, GA, USA

D. Thiruvaiyaru

e-mail: dthiruvi@aug.edu

S. Sethuraman

e-mail: ssethura@aug.edu
Methods In this single-center prospective study, 320 patients with ANVB were examined, of which 81 met the entry criteria for evaluation. All patients with ANVB underwent urgent endoscopy. Those with adherent clots on the ulcer base were sprayed with $250 \mathrm{ml}$ of water, followed by up to $100 \mathrm{ml}$ of $3 \% \mathrm{H}_{2} \mathrm{O}_{2}$. The main outcome measurement was Kalloo's Visual Scores of the ulcer base before and after water and $\mathrm{H}_{2} \mathrm{O}_{2}$.

Results Eighty-one patients with gastric ulcers (GU; 34) and duodenal ulcers (DU; 47) met the entry criteria. The mean improvement in grade from water to $\mathrm{H}_{2} \mathrm{O}_{2}$ was 2.04 (95\% confidence interval $[\mathrm{CI}](1.86,2.23))$. The mean volume of $\mathrm{H}_{2} \mathrm{O}_{2}$ used to clear clots was higher $(70 \mathrm{ml})$ in patients who were negative for both Helicobacter pylori and non-steroidal anti-inflammatory drug (NSAID) use than in those who were positive for both $(31 \mathrm{ml})$ $(P=0.00)$. More DU patients $(72 \%)$ had visible vessels than GU patients $(44 \%)(P=0.01)$.

Conclusions $\mathrm{H}_{2} \mathrm{O}_{2}$ improved the visualization of ulcer bases in ANVB. A smaller volume of $\mathrm{H}_{2} \mathrm{O}_{2}$ was required to clear clots in patients who used NSAIDs and had $H$. pylori infection. $\mathrm{H}_{2} \mathrm{O}_{2}$ identified more DU vessels. The use of $\mathrm{H}_{2} \mathrm{O}_{2}$ should be considered as a standard therapy in the management of clots in ANVB.

Keywords Non-variceal bleeding - Endoscopy ·

Ulcer clot · Hydrogen peroxide

\section{Introduction}

Upper gastrointestinal bleeding, a potentially lethal medical emergency, is a common cause for intensive care unit (ICU) admission. Bleeding is the most frequent complication of peptic ulcer disease, comprising $30-50 \%$ of all 
complications $[1,2]$. Peptic ulcer bleeding incidences in published studies vary from 6 to $78 \%$, depending on the geographic location of the study center [3].

During the past ten years, early endoscopy has been shown to significantly decrease the hospitalization days for patients with complicated peptic ulcer disease, especially for those with acute non-variceal bleeding (ANVB) [4]. Another advantage in performing early endoscopy on such patients is that it allows the endoscopist to assess the bleeding site by visualizing the base of the culprit lesion. This, in turn, facilitates more timely diagnosis, accurate assessment of the bleeding lesion, and endoscopic therapy (if needed), all of which ultimately reduce the likelihood of rebleeding $[5,6]$. These facts point to the importance of early endoscopy in the management of patients with ANVB.

It has been previously shown that early endoscopic therapy in ANVB is necessary for ulcers that have high-risk stigmata of rebleeding, such as actively spurting vessel, non-bleeding vessel, or ulcers with adherent clot, because each of them carries a rebleeding risk of $90 \%, 50 \%$, and $30 \%$, respectively, if endoscopic therapy is not offered. A lower risk of rebleeding is seen in patients having ulcers with pigmented spots (10\%) or clean base (5\%) [7-9]. But, early endoscopy in ANVB can be challenging, especially when blood and clots are present, obscuring the visualization of bleeding lesions that may prevent appropriate stratification of the risk of rebleeding. An adherent clot may simply cover a pigmented spot or a clean base which carry a low risk of rebleeding (10\% and 5\%, respectively) and are generally shown to not require endoscopic therapy [10-13]; an adherent clot may mask an underlying vessel which carries a high risk of rebleeding (50\%) and is therefore shown to require endoscopic therapy [5, 6]. Hence, it is extremely important to clear the adherent clot from the ulcer base and to visualize it in order to accurately assess the prognosis and to direct specific endoscopic treatment if indicated. This, in turn, results in improved outcomes for patients, i.e., lesser chance of rebleeding and its associated complications. Several methods have been used to remove adherent clots, such as vigorous washing with water and endoscopic removal by using a snare. Recent studies have shown that the removal of adherent clots by mechanical methods (shaving or trimming) without disturbing the pedicle may facilitate endoscopic therapy [14]. More recently, 3\% hydrogen peroxide $\left(\mathrm{H}_{2} \mathrm{O}_{2}\right)$ solution has been used in a few animal and small-sample human studies to clear the adherent blood clots to gain better visibility of the ulcer bases [15-17]. The rationale for using $\mathrm{H}_{2} \mathrm{O}_{2}$ is that it oxidizes the hemoglobin thus rendering the pigmented blood clot translucent and helping in its dissolution [18-20]. Additionally, its potential hemostatic effect may add to the list of adjunct therapies in the endoscopic management [21-23]. This is the first large-sample human study conducted so far to evaluate the efficacy of $\mathrm{H}_{2} \mathrm{O}_{2}$ in the visualization of ulcer bases. We tested the hypothesis that cleaning the ulcer base with $3 \%$ $\mathrm{H}_{2} \mathrm{O}_{2}$ solution improves the endoscopic visualization of ANVB lesions compared to cleaning with water alone.

\section{Patients and Methods}

All patients aged 18 years or older who presented to a single tertiary care center between March 2003 and December 2008 with acute upper gastrointestinal bleeding (melena or fresh blood per rectum or vomiting of fresh blood) were considered for the study. A total of 320 patients were evaluated for the study protocol (130 female and 190 male). An informed written consent was obtained from each of those patients. Only patients with adherent clots on the ulcer base were included in the study. The following patients were excluded from the study: those who were unable to give consent, those with comorbidities such as severe cardiac failure, obstructive pulmonary disease, coagulation disorder, and neurological conditions, those who had a known allergy or sensitivity to hydrogen peroxide, and those who had adherent clots larger than $2 \mathrm{~cm}$ on an ulcer base. Therefore, only 81 of the 320 subjects met the inclusion criterion. The study was approved by the Institutional Review Board of the medical center.

Emergency upper gastrointestinal endoscopy was performed (Olympus double-channel therapeutic endoscope) on all patients within $6 \mathrm{~h}$ of presentation to the hospital by a single experienced endoscopist (SS). Upon admission to the hospital, all patients were administered IV proton pump inhibitor (PPI) bolus followed by continuous infusion. Gastric lavage with $500 \mathrm{ml}$ of water was performed on all patients using a 34Fr, 36" Argyle-Edlich Gastric Lavage $\mathrm{Kit}^{\mathrm{TM}}$ before endoscopy. All patients received a combination of fentanyl and midazolam for sedation prior to the procedure. Kalloo's Visual Clearance Scoring System (Kalloo Scoring) was used to assess the improvement in visual clearance of the clot from the ulcer bases. The grades according to this system were: grade " 0 " for no change, grade "1" for minimal clearance, grade "2" for good clearance, and grade " 3 " for excellent clearance [16]. During endoscopy, a visible vessel was defined as an elevated red, bluish, or pulsatile spot on the ulcer [17]. If clots were seen, the ulcer base was vigorously sprayed with $5-\mathrm{ml}$ aliquots of $250 \mathrm{ml}$ sterile water at room temperature mixed with $5 \mathrm{ml}$ of simethicone using a $5 \mathrm{Fr}$ spray tip catheter attached to a $30-\mathrm{ml}$ syringe and applying a constant pressure. Adherent clots were defined as those resistant to target water spray [16]. If water spray did not achieve at least a grade 2 clearance, then $5-\mathrm{ml}$ aliquots of $3 \%$ solution of $\mathrm{H}_{2} \mathrm{O}_{2}$ (USP, Cumberland Swan, Smyrna, TN) at room temperature was sprayed onto the ulcer base using a $5 \mathrm{Fr}$ 
spray tip catheter attached to a $30-\mathrm{ml}$ syringe for up to $100 \mathrm{ml}$ or until achieving a grade 3 clearance. A fresh bottle of $\mathrm{H}_{2} \mathrm{O}_{2}$ was used for each patient. The ulcer bases were sequentially visually scored before and after water and, finally, after hydrogen peroxide spray using Kalloo's Visual Clearance Scoring System as mentioned above. Multiple photographs were obtained at each stage of management for subsequent evaluation of the grades of visibility of the ulcer bases by two independent observers. The patient's stomach was aspirated repeatedly and completely after each aliquot of $\mathrm{H}_{2} \mathrm{O}_{2}$. The bubbles and effervescence created by $\mathrm{H}_{2} \mathrm{O}_{2}$ were thoroughly washed off with approximately $30 \mathrm{ml}$ of sterile water mixed with simethicone, as described earlier. The endoscopist proceeded with the standard therapeutic procedure as deemed appropriate for each patient. Initial hemostasis was defined as cessation of bleeding for $5 \mathrm{~min}$ after endoscopic therapy. Helicobacter pylori status was assessed on gastric mucosal biopsies (obtained from the antrum and the body) by rapid urease test in all patients and non-steroidal anti-inflammatory drug (NSAID) use history was recorded. All of the study subjects were followed for $48 \mathrm{~h}$ in the hospital and subsequently for 30 days after the index endoscopy for recurrence of bleeding, need for blood transfusion or surgery, and adverse reaction to $\mathrm{H}_{2} \mathrm{O}_{2}$.

The primary end points of the study were Kalloo's Visual Clearance Scores before and after water spray and, finally, after $\mathrm{H}_{2} \mathrm{O}_{2}$. The secondary end point was the volume of $\mathrm{H}_{2} \mathrm{O}_{2}$ used to clear ulcer clots. All statistical analyses were performed using the software package SPSS 11.5. A univariate repeated measures analysis of variance (ANOVA) procedure was conducted to study the effect of cleaning the ulcer base with water and $\mathrm{H}_{2} \mathrm{O}_{2}$ on the grades of visibility. Another univariate ANOVA procedure was conducted to study the volume of $\mathrm{H}_{2} \mathrm{O}_{2}$ required to clean the ulcer base with factors impacting it, such as age, use of tobacco, alcohol, PPI and NSAID use, $H$. Pylori status, and the ulcer site (duodenal ulcers [DU] or gastric ulcers [GU]). All of the photographs were graded independently by two endoscopists (SS and RRS) for intra- and inter-observer agreement. The second endoscopist (RRS) was blinded to the study results and also to the photographs. Post-hoc analysis was performed utilizing Tukey's honestly significant differences (HSD) and Bonferroni's multiple comparison procedures.

\section{Results}

Of the 320 eligible subjects, 81 patients ( 33 females and 48 males) 22-88 years of age fulfilled the entry criteria of the study (adherent clots on ulcer base). A total of $34 \mathrm{GU}$ and 47 DU were noted (Table 1). A total of 40 patients reported a recent history of NSAID use (for more than 1 month) and 58 patients tested positive for $H$. pylori on gastric biopsies.
Table 1 Patient demographics

\begin{tabular}{ll}
\hline Demographics & \\
\hline Mean age (range 22-88 years) & $59($ SD 17.67) \\
& No $(\%)$ \\
Male & $48(59)$ \\
Female & $33(41)$ \\
H. pylori positive & $58(72)$ \\
NSAID use & $40(49)$ \\
PPI use & $13(16)$ \\
Smoking & $22(27)$ \\
Alcohol use & $30(37)$ \\
Duodenal ulcers & $47(58)$ \\
Gastric ulcers & $34(42)$ \\
\hline
\end{tabular}

All patients completed the study successfully and none of them developed adverse effects of $\mathrm{H}_{2} \mathrm{O}_{2}$ for up to $48 \mathrm{~h}$ after the procedure (nausea, vomiting, or abdominal pain).

The mean grades of visualization of the ulcer beds prior to and immediately after water and then after hydrogen peroxide spraying were obtained. The mean grades were 0.06 before water, 0.78 after water, and 2.83 after $\mathrm{H}_{2} \mathrm{O}_{2}$ (Table 2). The mean difference in grade improvements between water and hydrogen peroxide spray was $2.04(95 \%$ confidence interval [CI] $(1.86,2.23))$. This difference was found to be statistically significant $(P=0.00)$ (Figs. 1 and 2). $\mathrm{H}_{2} \mathrm{O}_{2}$ improved the visibility of both types of peptic ulcers, but more so in DU than in GU (Fig. 3). The difference in the improvement in grades from water to $\mathrm{H}_{2} \mathrm{O}_{2}$ between DU and GU showed a mean of 0.43 (95\% CI 0.03 , $0.84)(P=0.035)$. In no patient did water spray alone clear the adherent ulcer base clots (Table 2).

Following clot clearance using $\mathrm{H}_{2} \mathrm{O}_{2}$ in the 81 subjects, $49(60.5 \%)$ demonstrated visible vessels and $32(39.5 \%)$ demonstrated pigmented spots. Further analysis of visible vessel count using the Chi-square test showed that the proportion of visible vessels in DU patients (34 of 47 [72\%]) was significantly higher $(P=0.01)$ than in $\mathrm{GU}$ patients (15 of 34 [44\%]).

The univariate ANOVA procedure conducted to study the volume of $\mathrm{H}_{2} \mathrm{O}_{2}$ required to clean the ulcer base revealed that NSAID use, $H$. pylori status, and the ulcer site were the only significant factors impacting the volume required. Post-hoc analysis of volume such as Tukey's HSD and Bonferroni's multiple comparison procedures revealed that the mean volume $(31 \mathrm{ml})$ of $\mathrm{H}_{2} \mathrm{O}_{2}$ used in patients who tested positive for $H$. pylori and also took NSAIDs was significantly lower than the mean volume $(70 \mathrm{ml})$ used in patients who were negative for both $(P$ value 0.00$)$. The mean volumes $(35$ and $33 \mathrm{ml})$ of hydrogen peroxide used in patients with DU or GU who took NSAIDs were significantly lower than those of (45 

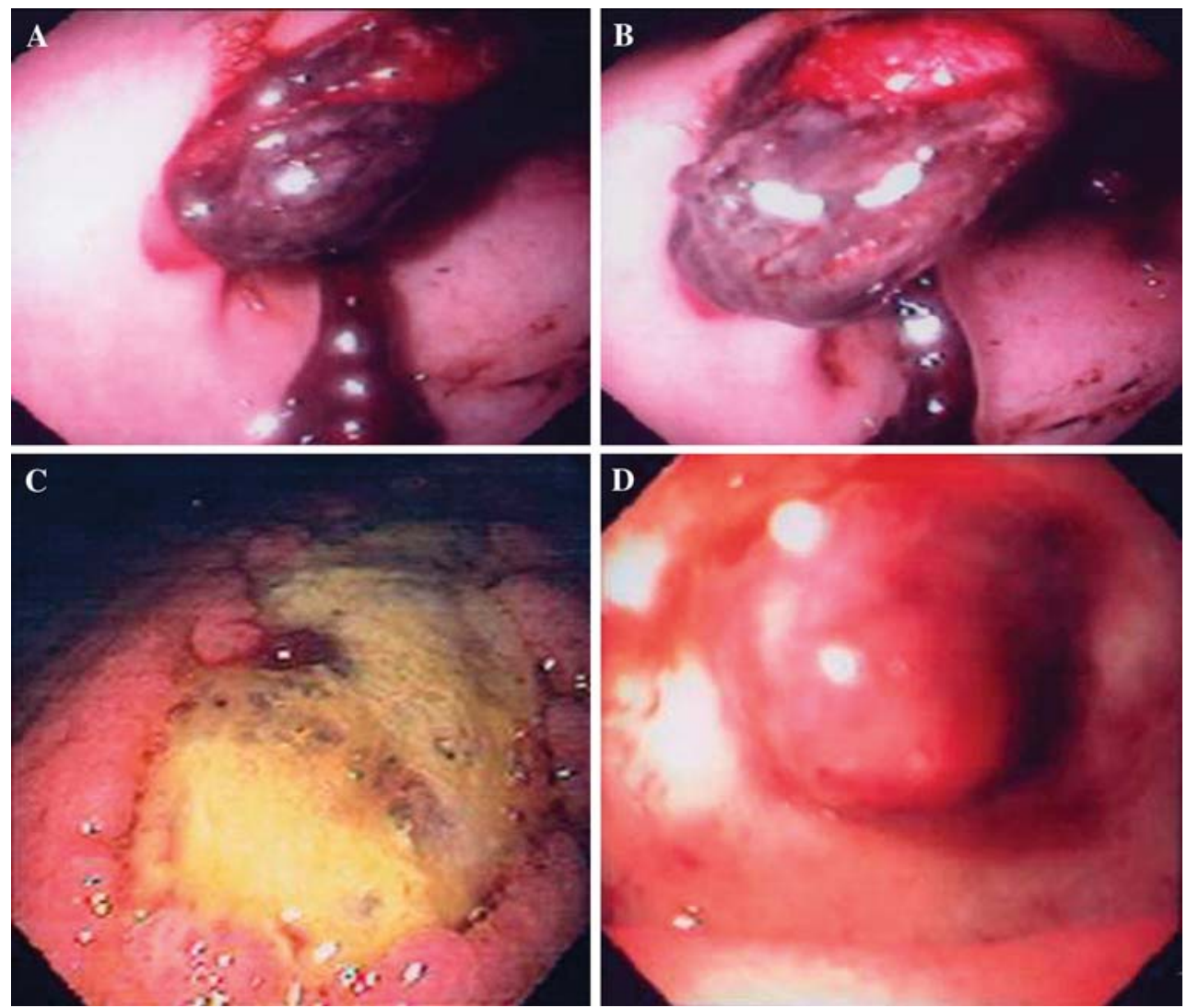

Fig. 1 a Before water. b After water. c Effervescence during hydrogen peroxide. d After hydrogen peroxide

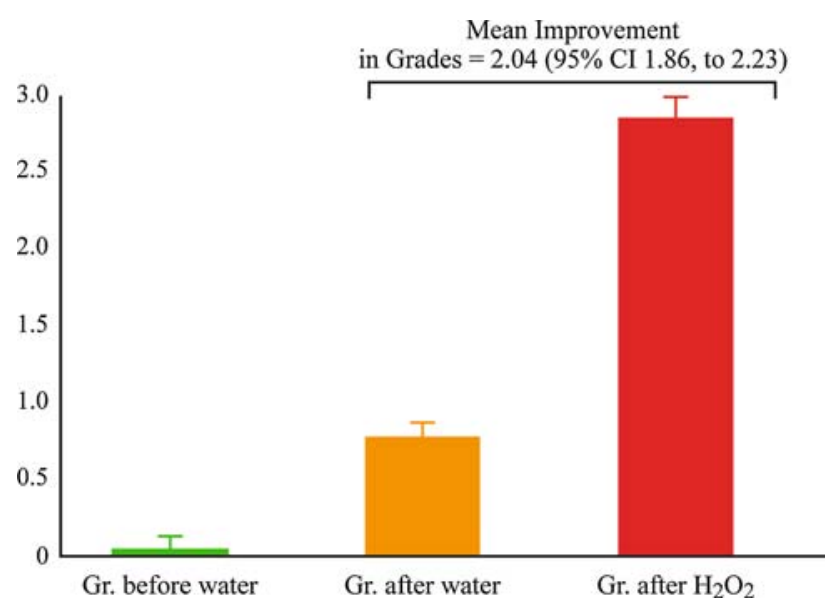

Fig. 2 Grades achieved with water and $\mathrm{H}_{2} \mathrm{O}_{2}$

and $56 \mathrm{ml})$ patients with DU or GU who did not take NSAIDs $(P<0.05$, Tamhane and Dunnett T3 multiple comparison tests) (Table 3, Fig. 4).

The Kappa statistic was calculated to measure the intraobserver agreement (SS) of the grades of visibility of the ulcer bases assigned by the primary endoscopist before and after water, and after $\mathrm{H}_{2} \mathrm{O}_{2}$. The agreement was found to be substantial as well as statistically significant for each pair of grades (Kappa 0.64 (95\% CI $(0.32,0.97)), 0.82$ (95\% CI

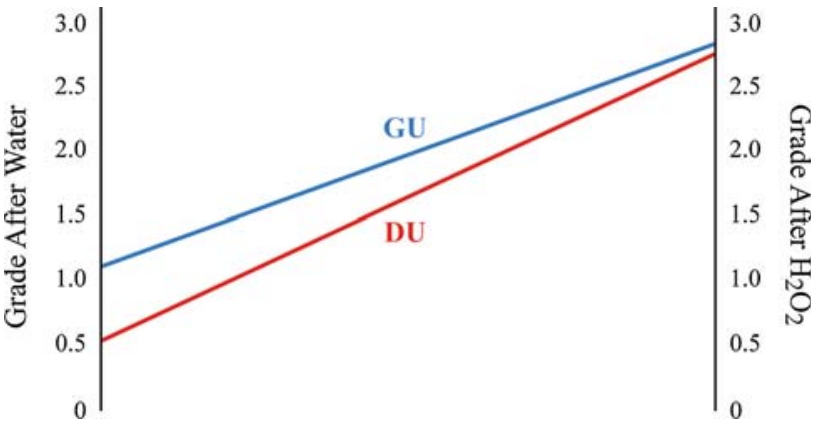

Fig. 3 Grades of visibility of gastric and duodenal ulcers (GU and DU)

Table 2 Grades achieved before and after water and after hydrogen peroxide

\begin{tabular}{llll}
\hline Grades achieved & Mean grade & Std. error & $95 \%$ CI \\
\hline Before water & 0.06 & 0.24 & $0.01,0.12$ \\
After water & 0.78 & 0.76 & $0.61,0.95$ \\
After hydrogen peroxide & 2.83 & 0.38 & $2.74,2.91$ \\
\hline
\end{tabular}

$(0.72,0.93))$, and $0.74(95 \% \mathrm{CI}(0.55,0.94))$ and a $P$-value of 0.0001 for each pair). The inter-observer agreement of the grades of visibility before water, after water, and after $\mathrm{H}_{2} \mathrm{O}_{2}$ between the two observers were also found to be substantial, 
Table 3 Impact of $H$. pylori state and NSAID use on the volume of $\mathrm{H}_{2} \mathrm{O}_{2}$ used

\begin{tabular}{llllr}
\hline & CLO +ve, NSAID +ve & CLO - ve, NSAID +ve & CLO +ve, NSAID -ve & CLO - ve, NSAID -ve \\
\hline $\begin{array}{l}\text { Number of patients } \\
\text { Volume of } \mathrm{H}_{2} \mathrm{O}_{2}\end{array}$ & 29 & 11 & 29 & 12 \\
Maximum & 40 & 54 & 55 & 100 \\
Q3 & 35 & 45 & 40 & 70 \\
Median & 30 & 40 & 35 & 67 \\
Q1 & 27 & 35 & 35 & 60 \\
Minimum & 20 & 20 & 27 & 55 \\
Mean & 31.4 (SD 5.96) & 40.9 (SD 9.17) & 38.8 (SD 8.31) & 70 (SD 15.08) \\
\hline
\end{tabular}

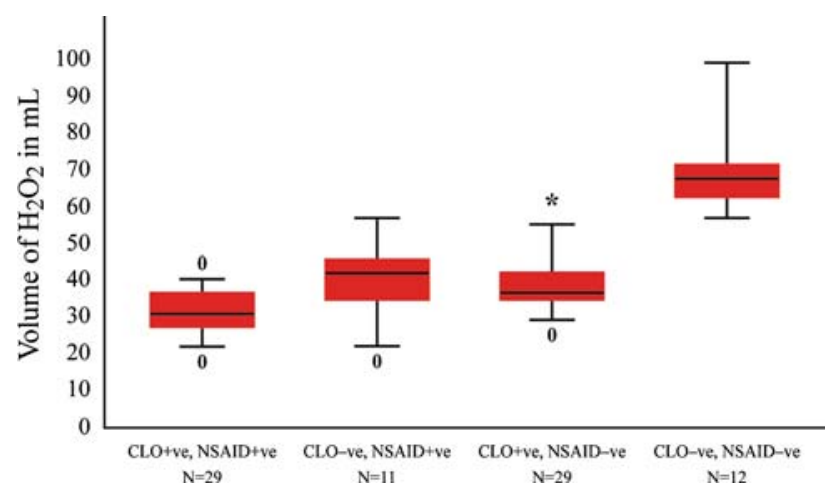

Fig. 4 Impact of $H$. pylori state and NSAID use on the volume of $\mathrm{H}_{2} \mathrm{O}_{2}$ used

as well as statistically significant (Kappa 0.78 (95\% CI $(0.50,1)), 0.80(95 \% \mathrm{CI}(0.70,0.92))$, and $0.75(95 \% \mathrm{CI}$ $(0.57,0.94))$ and a $P$-value of 0.0001 for each pair).

No bleeding was induced during the administration of $\mathrm{H}_{2} \mathrm{O}_{2}$. No further intervention was required for the ulcer bed visualization in any of the study subjects. In the 30-day follow up, one DU patient with a vessel had recurrence of bleeding on day 2 requiring 2 units of packed red-cell transfusion and surgery, one DU patient with pigment spot on the ulcer base had recurrence of bleeding on day 23 requiring endoscopic therapy, one GU patient with pigmented spot died of complicated myocardial infarction on day 14 , and one patient died in a motor vehicle accident on day 19.

\section{Discussion}

In this large-number single-center prospective study of 81 subjects presenting with ANVB, excellent improvement in visualization (improvement to grade 3) of ulcer bases was achieved after cleaning with $3 \% \mathrm{H}_{2} \mathrm{O}_{2}$ spray. During the last ten years, early endoscopy and treatment of ANVB patients within $24 \mathrm{~h}$ of admission has proven to be costeffective because it reduces the length of hospitalization. Emergency upper gastrointestinal endoscopy in patients with acute gastrointestinal bleeding not only facilitates the diagnosis and therapy, but it also provides extremely valuable information regarding the risk of rebleeding and the need for subsequent surgery. Endoscopic therapy is usually necessary for ulcers with stigmata of high risk of rebleeding such as actively spurting, non-bleeding vessel, or ulcers with adherent clot $[14,24]$. Endoscopic therapy is more straightforward for clearly visible peptic ulcers with actively spurting vessel or non-bleeding visible vessel, but for the management of ulcers with adherent clot, it has been controversial. An adherent clot obscures the underlying stigmata of the ulcer base which may be a vessel or a pigmented spot and therefore the risk of subsequent bleeding in patients with such clots may be misleadingly high (50\%) or low (10\%) [7-9]. Recently, several methods have been used in an attempt to remove adherent clots; these include vigorous washing with water and endoscopic removal by using a snare. These endoscopic methods adequately enable the endoscopist to visualize bleeding lesions [10-13], but in some patients, these standard endoscopic methods may not be sufficient to remove clots from ANVB sources and hence may lead to improper risk stratification and assessment of prognosis. In these situations, the use of $3 \% \mathrm{H}_{2} \mathrm{O}_{2}$ is effective in clearing the adherent blood clots, allowing for better visualization of ulcer bases when water irrigation alone is not sufficient. This would facilitate the appropriate endoscopic assessment and appropriate hemostatic therapy for ANVB.

In our study, the mean volume of hydrogen peroxide required to achieve grade 3 clearance on Kalloo's score was significantly lower in patients who tested positive for $H$. pylori and who also took NSAIDs. The higher prevalence of $H$. pylori observed amongst DU when compared to GU patients could explain the reduced volume of $\mathrm{H}_{2} \mathrm{O}_{2}$ required to clear clots in the DU patients. This is likely due to the fact that clots in patients who have had prior NSAID use and $H$. pylori infection may be less stable due to the greater platelet dysfunction. However, further studies must be done to address this finding, given the potentially poor sensitivity of the rapid urease test for $H$. pylori detection in those with bleeding ulcers. The clinical significance of the 
differences in $\mathrm{H}_{2} \mathrm{O}_{2}$ volumes required to clear clots in the other groups remains to be determined.

Our study demonstrated $60 \%$ visible vessels and $40 \%$ pigmented spots, which is similar to previous studies on peptic ulcer stigmata after clot removal using mechanical methods [25, 26]. It is interesting to note that subgroup analysis on our study subjects demonstrated a significantly higher number of visible vessels in patients with DU than GU. We hypothesize that this difference is presumably due to the presence of larger caliber vessels in the DU bases when compared to GU bases.

We do acknowledge the fact that our study had a few limitations such as a subjective scoring system (Kalloo), lack of control subjects, and a possible introduction of observer bias, as the primary endoscopist was not blinded to the study. However, we have shown that the intra- and inter-observer agreement are substantial and statistically significant, through Kappa statistics, and have, thus, demonstrated the consistency in grading by the primary endoscopist and his similarity in grading with the independent observer. Further validation of our study results by multicenter trials may be needed. A potential limitation of the use of $\mathrm{H}_{2} \mathrm{O}_{2}$ is that it may not be useful in improving the visibility of ulcer bases with clots larger than $2 \mathrm{~cm}$. This was the case in a small number (16) of patients from our unpublished observations.

$\mathrm{H}_{2} \mathrm{O}_{2}(3 \%)$ is known to be relatively non-toxic and, accordingly, no adverse effects were encountered in this trial. $\mathrm{H}_{2} \mathrm{O}_{2}$ oxides hemoglobin, and facilitates clot dissolution and clearance. Additionally, it has a potential hemostatic effect, which may add to other adjunctive therapies in the endoscopic management of ANVB [1923]. We conclude that $3 \% \mathrm{H}_{2} \mathrm{O}_{2}$ has the potential to be safe and extremely valuable in the improved visualization of lesions in patients with ANVB. More importantly, $\mathrm{H}_{2} \mathrm{O}_{2}$ effectively identifies visible vessels under adherent clots without the use of mechanical methods, which are known to induce bleeding and are technically more difficult to implement. Therefore, $\mathrm{H}_{2} \mathrm{O}_{2}$ may prove to be a better alternative to mechanical methods for clot removal. Hence, the use of $\mathrm{H}_{2} \mathrm{O}_{2}$ should be considered as a standard therapy to improve the visualization of ulcers with adherent clots in patients with ANVB.

\section{Conclusion}

\section{What Is Already Known on This Topic}

- Hydrogen peroxide has been shown to clear peptic ulcer clots in animal studies and in small-sample human studies.
What This Study Adds to Our Knowledge

- This is the first large-sample human study wherein hydrogen peroxide is shown to clear ulcer clots in patients with acute non-variceal upper gastrointestinal bleeding.

- Patients who take non-steroidal anti-inflammatory drugs (NSAIDs) and have Helicobacter pylori infection require a smaller volume of hydrogen peroxide to clear ulcer clots.

- The use of hydrogen peroxide identified more visible vessels in patients with duodenal ulcers than in patients with gastric ulcers.

Open Access This article is distributed under the terms of the Creative Commons Attribution Noncommercial License which permits any noncommercial use, distribution, and reproduction in any medium, provided the original author(s) and source are credited.

\section{References}

1. Silverstein FE, Gilbert DA, Tedesco FJ, et al. The national ASGE survey on upper gastrointestinal bleeding. I. Study design and baseline data. Gastrointest Endosc. 1981;27:73-79.

2. Silverstein FE, Gilbert DA, Tedesco FJ, et al. The national ASGE survey on upper gastrointestinal bleeding. II. Clinical prognostic factors. Gastrointest Endosc. 1981;27:80-93.

3. Morgan AG, Clamp SE. OMGE international upper gastrointestinal bleeding survey, 1978-1986. Scand J Gastroenterol Suppl. 1988;144:51-58.

4. Cooper GS, Chak A, Way LE, et al. Early endoscopy in upper gastrointestinal hemorrhage: associations with recurrent bleeding, surgery, and length of hospital stay. Gastrointest Endosc. 1999; 49:145-152.

5. Rockall TA, Logan RFA, Devlin HB, et al. Selection of patients for early discharge or outpatient care after acute upper gastrointestinal haemorrhage. National Audit of Acute Upper Gastrointestinal Haemorrhage. Lancet. 1996;347:1138-1140.

6. Lee JG, Turnipseed S, Romano PS, et al. Endoscopy-based triage significantly reduces hospitalization rates and costs of treating upper GI bleeding: a randomized controlled trial. Gastrointest Endosc. 1999;50:755-761.

7. Jensen DM. Endoscopic control of nonvariceal upper gastrointestinal hemorrhage. In: Yamada T, Alpers DH, Laine L, et al., eds. Textbook of gastroenterology. 3rd ed. Philadelphia: Lippincott Williams \& Wilkins; 1999:2857-2879.

8. Johnston JH. Endoscopic risk factors for bleeding peptic ulcer. Gastrointest Endosc. 1990;36(5 Suppl):S16-S20.

9. Laine L, Peterson WL. Bleeding peptic ulcer. $N$ Engl J Med. 1994;331:717-727.

10. Chung SC, Sung JY, Lai CW, et al. Epinephrine injection alone or epinephrine plus heat probe treatment for bleeding peptic ulcers: a randomized trial. Gastrointest Endosc. 1994;40:271.

11. Chung SS, Lau JY, Sung JJ, et al. Randomised comparison between adrenaline injection alone and adrenaline injection plus heat probe treatment for actively bleeding ulcers. BMJ. 1997;314: 1307-1311.

12. Jensen DM, Kovacs TO, Randall GM, et al. Prospective study of thermal coagulation (Gold probe) vs. combination injection and 
thermal treatment of high risk patients with severe ulcer or Mallory-Weiss bleeding. Gastrointest Endosc. 1994;40:25.

13. Laine L, Cohen H, Brodhead J, et al. Prospective evaluation of immediate versus delayed refeeding and prognostic value of endoscopy in patients with upper gastrointestinal hemorrhage. Gastroenterology. 1992;102:314-316.

14. Adler DG, Leighton JA, Davila RE, et al. ASGE guideline: the role of endoscopy in acute non-variceal upper-GI bleeding. Gastrointest Endosc. 2004;60(4):497-504.

15. Kalloo A, Hill S, Wadwa KS, et al. The utility of hydrogen peroxide in the management of acute gastrointestinal bleeding (AGIB) in a canine model: a placebo controlled randomized trial. Am J Gastroenterol. 1996;91:1915.

16. Kalloo AN, Canto MI, Wadwa KS, et al. Clinical usefulness of $3 \%$ hydrogen peroxide in acute upper GI bleeding: a pilot study. Gastrointest Endosc. 1999;49(4 Pt 1):518-521.

17. $\mathrm{Wu} \mathrm{DC}, \mathrm{Lu} \mathrm{CY}, \mathrm{Lu} \mathrm{CH}$, et al. Endoscopic hydrogen peroxide spray may facilitate localization of the bleeding site in acute upper gastrointestinal bleeding. Endoscopy. 1999;31(3):237-241.

18. Henry MC, Wheeler J, Mofenson HC, et al. Hydrogen peroxide 3\% exposures. J Toxicol Clin Toxicol. 1996;34:323-327.

19. Akane A. Hydrogen peroxide decomposes the heme compound in forensic specimens and improves the efficiency of PCR. Biotechniques. 1996;21:392-394.
20. White DC, Teasdale PR. The oxygenation of blood by hydrogen peroxide: in vitro studies. Br J Anaesth. 1966;38:339-344.

21. Hankin FM, Campbell SE, Goldstein SA, et al. Hydrogen peroxide as a topical hemostatic agent. Clin Orthop Relat Res. 1984;186:244-248.

22. Mark JR. Hydrogen peroxide for hemostasis [letter]. Neurosurgery. 1986;18:827.

23. Epstein JA. Hydrogen peroxide for hemostasis [letter]. Neurosurgery. 1987;20:63.

24. Barkun A, Bardou M, Marshall JK; Nonvariceal Upper GI Bleeding Consensus Conference Group. Consensus recommendations for managing patients with nonvariceal upper gastrointestinal bleeding. Ann Intern Med. 2003;139(10):843-857.

25. Bini EJ, Cohen J. Endoscopic treatment compared with medical therapy for the prevention of recurrent ulcer hemorrhage in patients with adherent clots. Gastrointest Endosc. 2003;58(5): 707-714.

26. Bleau BL, Gostout CJ, Sherman KE, et al. Recurrent bleeding from peptic ulcer associated with adherent clot: a randomized study comparing endoscopic treatment with medical therapy. Gastrointest Endosc. 2002;56(1):1-6. 